\title{
ICT-based Innovation and Employability for Women
}

\author{
https://doi.org/10.3991/ijep.v7i2.6758 \\ Marios A. Pappas \\ National Center for Scientific Research "Demokritos", Agia Paraskevi, Attica, Greece \\ mpapeit.demokritos.gr \\ Yannis Papagerasimou \\ National Center for Scientific Research "Demokritos", Agia Paraskevi, Attica, Greece \\ ypapa@it.demokritos.gr \\ Athanasios S. Drigas \\ National Center for Scientific Research "Demokritos", Agia Paraskevi, Attica, Greece \\ dr@iit.demokritos.gr \\ Dimitris Raftopoulos \\ National Center for Scientific Research "Demokritos", Agia Paraskevi, Attica, Greece \\ dreiit.demokritos.gr \\ Pantelis Nikolaidis \\ National Center for Scientific Research "Demokritos", Agia Paraskevi, Attica, Greece \\ dreit.demokritos.gr
}

\begin{abstract}
The utilization of ICTs in creating new jobs and eliminating gender based inequalities in employability and entrepreneurship, employs increasingly more researchers, governments and organizations around the world. In this article we analyze the current situation regarding the impact of ICTs, social networks and media on creating new opportunities for the employability of women. We also present the new market requirements, the new e-skills that will be acquired by women in order to take advantage of new labor market opportunities. Finally special reference is made to new trends in women's entrepreneurship as well as the supportive role of ICTs.
\end{abstract}

Keywords-ICT, Female Entrepreneurship, ICT-based Innovation, ICT-skills, Employability for Women, Labor Market.

\section{Introduction}

Today, it is commonly accepted that digital literacy ${ }^{1}$ constitutes a global priority. The rapid development of digital technologies, in particular of Information and Communications Technologies (ICTs) worldwide, creates major challenges for smart,

\footnotetext{
${ }^{1}$ The term Digital Literacy describes the utilization and comprehension of information in the digital age (Gilster, 1997)
} 
sustainable and inclusive growth. ICT tools and services generate opportunities for growth and investment in developed and developing countries. New professions are created, based on these technologies, as well as existing professions adapt to them, leading to the transformation of the old economy. The integration of ICTs into large, medium and small enterprises leads to upgrading of production, design and marketing, while providing opportunities for innovative practices.

Digital economy as well as ICT sectors grow seven times faster than the rest of the economy and is therefore one of the seven key flagship initiatives of the Europe 2020 strategy (European Commission, 2011). Having to face these new standards in the global labor market, governments, businesses and employees should adapt and get ready to take advantage of the upcoming development of the ICT sector. It is observed that despite the high unemployment levels and the economic crisis, there is a lack of qualified staff in ICT.

At the same time as most studies indicate, Europe faces an increasingly widening gap of digital skills. This is subsequently an important cause for concern, just because of the strategic importance of Information and Communication Technologies (ICTs) to achieve the EU's objectives in relation to a more competitive international economy. This situation is worrying but also promising for the future of young skilled employees, especially from vulnerable groups who may have disadvantages in the labor market so far.

In addition to the existing problem of lack of ICT executives in the European labor market, there is also the problem of low representation of women in occupations related to ICTs. It is a great contradiction that while research indicates that strong female presence in business leads to more effective decisions, and women demonstrate greater creativity and efficiency, however they are only $30 \%$ of workers in ICT jobs in Europe and only $9 \%$ of the applications have been created by women.

According to the European Commission, inclusive growth refers to the creation of jobs (especially for women, young and older workers), the investment in skills and lifelong education in order to help people of all ages to anticipate and manage different situations, the modernization of labor market and welfare systems and finally the equitable distribution of the benefits of growth to all European Union countries.

In this article we were based on the modern literature to describe and analyze the new working environment emphasizing on the use of ICT tools (web and social media), to investigate and study the major European initiatives and best practices to strengthen the role of women in the field of ICTs and to launch women in digital skills, as well as to investigate the role of ICTs on women entrepreneurship and innovation and their utilization for the new trends of employability.

In the labor market nowadays, women and men have the same privileges and the same opportunities?

Which are considered as the most important employability skills prevailing in today's digital age?

The utilization of ICT could create new jobs and opportunities for entrepreneurship for women?

This research was based on the review of the current literature on the basis of published studies and reports of the last years. Bringing together all the existing 
knowledge of the subject, we assessed and linked the results of individual studies in order to draw any conclusions and proposals for the future as regards to the ICTbased employability and entrepreneurship for women.

\section{Gender and Employment}

Despite the existence of institutionalized provisions and laws on gender equality, every day there are observed actions of discrimination against women in the workplace. The legislative equality sometimes contradicts daily practice, as there are essential gender-based distinctions, as regards access to the labor market, remuneration policy and benefits, as well as career development and labor relations.

In many cases, women face prejudice and distrust in their working environment, even if they have more qualifications than their male colleagues. As a result of these prejudices and stereotypes, women rarely possess positions of high responsibility, as management positions.

\subsection{Glass Ceiling}

Despite the fact that in recent years women claim their share in the labor market on equal terms, most business executives in key positions are men. Glass ceiling could be defined as the reason why there is a limited participation of women in positions of responsibilities, such as managers, human resources and other posts which demand executive job (Arfken et al, 2004). Reduced participation of women in decision making could be found in both the public and the private sector and also in politics.

The belief that exists at a large portion of the labor market is that women lack in leadership skills in comparison to men, is a factor for the reduced women's assess to positions of expanded duties. Moreover the behavior required in the role of the leader is considered incompatible with the beliefs of the people on the desirable female behavior. According to Jackson and O'Callaghan (2009), female employees face 'the lack of expatriate assignments and international experience' that prevents their promotion to the highest levels of the corporate hierarchy.

The first step that young women should follow in order to break the glass ceiling is to set goals and make the effort to reach them. They should detach themselves from stereotypes and learn from senior women in management (Baumgartner and Scheider, 2010).

\subsection{Remuneration Policy}

Indicative of the ongoing gender based differentiation is the pay gap between women and men. This gap is a result of the disparagement of women's skills and professional qualifications as well as the difference in hourly compensation depending on the quality of work. Mandel and Shalev (2009) highlighted the important role of wage inequality within classes which determines the women's exclusion from positions with high responsibilities. According to figures published by the General of 
Justice of European Commission in 2014, women across the European Union earn on average around $16.4 \%$ less than men, despite the fact that for years there are voted provisions in order to close the gender pay gap (European Pact for Gender Equality, 2011 and Actions on gender equality agreed between the European social partners, 2005).

According to the U.S. Bureau of Labor Statistics, in 2015 the median gap in median annual earnings was $20 \%$, as the median annual earning for full time male employees in United States was 51,212 compared to 40,742 for female employees. According to the Workplace Gender Equality of the Australian Government (2016) men are paid $17.3 \%$ more than women, as their full-time average weekly earnings are $277.70 \$$ more than in women.

\subsection{Part-Time Jobs}

The economic recession in Europe and the comparatively high cost of the permanent staff for companies, contributed to part-time work, which appears in the form of fixed term contracts or sometimes in the form of 'rental' employees.

The Dutch part-time employment model is considered to be the new trend for young women. Nowadays, $60 \%$ of employed women in Netherlands work 30 hours or less. The propensity to work part-time significantly increased for women born after the 1950s (Bosch, Deeten \& Euwals, 2010). There are two conflicting viewpoints about women working at part time jobs. On the one hand, part time jobs could be accused of under-utilization of highly educated women. On the other hand part time jobs provide an opportunity for women to work less and to be able to deal in parallel with other things, such as raising their children (Booth and Van Ours, 2010).

\subsection{Family and Job Balance}

A question that concerns young women in recent years is "Should I choose Career or Family?" Continuously increasing demands of the labor market, competition, long working hours, stress and pressure, are only a few factors which contribute to family and career to be considered as two incompatible concepts. However, numerous examples of modern women which managed a balance between work and family, weakened this belief. Women have to find on their own solutions in order to integrate their family and career role. According to successful women's perspectives, family should be the first priority, as mothers should be involved in their children's activities and life, but there is no need to spend the whole day with them (Cheung and Halpern, 2010).

The successful combination of work and family is greatly influenced by the conditions of work, as well as by the quality of life of each individual (Laurijssen \& Glorieux, 2013). Vanderpool \& Way (2013) stated that employees who face difficulties to balance career and family were more likely to present job anxiety and as a result to drop their performance or to give up their jobs. 


\subsection{Sexual Harassment}

Sexual harassment is considered to be a major barrier for career development of women and may be accompanied by decreased job satisfaction, lower organizational commitment, or increased withdrawal behaviors. An incident of sexual harassment in the workplace could cause disturbances in physical and mental health and in some cases post-traumatic disorders (Willness, Steel \& Lee, 2007). According to the report of the European Union Agency for Fundamental Rights (2014), 'sexual harassment is more commonly experienced by women in the highest occupational groups, as $75 \%$ of women in the top management category have experienced sexual harassment in their life time'.

Companies should spend time and resources in order to make serious policies against sexual harassment. In order for these policies to be effective, companies should organize monthly meetings, sexual harassment training sessions and take immediate action for any occurrence becomes known (Roberts \& Mann, 1996). Lim \& Cortina (2005) proposed that eliminating all elements of a hateful work environment could be more effective, as there is possible correlation between general incivility and sexual harassment.

\section{New Trends in Employability Skills}

\section{1 e-Skills}

Nowadays, information and communication technologies evolve rapidly. Lack of skilled personnel in ICT could result in loss in competitiveness of the economy. European countries should invest in education and adapt their educational system in order to prepare employees for the ICT business, as well as for the e-Government base (Doucek, 2011).

Employees and unemployed who wish to join the workplace should keep up with the times and constantly train their ICT skills in order to benefit from the new business opportunities in the evolving labor market (Várallyai \& Herdon 2010). Based on current data, companies require from employees more than a specific job skill, as skills in particular technologies are considered essential in most jobs (Gourova, Antonova \& Nikolov 2006). Governments, educational institutions and industries should contribute to the educational process in order to enable new employees to meet the demands of the labor market.

Training in ICTs could help women to develop basic digital skills, overcome language barriers and gain confidence in their ability to learn new things (Garrido, Sullivan \& Gordon, 2010). Recent studies (Felstead, Gillie, \& Zhou, 2007; Riley, 2007) reveal the relationship between ICT skills - employability and especially on the effect of computer skills on compensation and opportunities for upward mobility. In particular, a study by Green et al. (2007) shows that computer skills have significant impact on pay (5.3\% and $6 \%$ for men and women, respectively). 


\section{2 e-Mentoring}

E-mentoring is a process through which specialized and experienced professionals teach, counsel and give practical guidance based on their knowledge to newcomers in the labor market. However e-mentoring could be based on bidirectional mentoring and information exchange, for example between colleagues where there will be mutual benefit from this relationship (Bierema \& Merriam, 2002).

E-mentoring seems to be a significantly useful tool for aspiring women managers, which is able to transcend boundaries such as geographical, demographic, functional or hierarchical, giving access to more and more people (Headlam-Wells, 2004). In addition to the development of specific skills, e-mentoring may contribute so that mentees gain inspiration and take psychological advantage for their career and personal development (Headlam-Wells, Gosland \& Craig, 2006).

\section{$4 \quad$ Labor Market Trends}

In developing countries seeking sustainable economic development, ICTs are considered a means for the gradual disengagement of the economy from low-value-added primary sectors such as agriculture. However, a business (economic) model which was successfully implemented in a developed economy, might not lead to the same results in a developing economy. Investment in ICT for developing countries should aim to counterbalance the disadvantages of the economy and create new products and services to join actively the global market place, while developed economies should take advantage of ICTs to improve the existing products and services (Roztocki \& Weistroffer, 2009).

More and more companies are investing in social media in order to strengthen their influence. As the social networking sites such as Facebook, Twitter and LinkedIn have become very popular among all age groups, companies create brand fan pages in order to enhance the relationship with their customers and increase their popularity. Ease of use and interactivity of digital tools enable customers to evaluate their experience after each purchase and in this way help the firm as well as other consumers with their comments (De Vries, Gensler \& Leeflang, 2012). In an effort to create effective social media campaigns, companies should take into account that people in their majority use the social media as entertainment tools and as a way to escape from daily problems. Therefore, campaigns should be differentiated from those of other brands and exploit all necessary means to attract customers. Furthermore, effective social media campaigns should follow the new market trends and meet current consumer demands in order to result in band loyalty from the perspective of customers (Erdoğmuş \& Cicek, 2012).

As expected, current economic conditions affect the investment in ICTs. Organizations which in periods of economic growth invest in the ICT sector, in times of recession and uncertainty reduce this expenditure (Underwood \& Khosrowshahi, 2012). 


\section{$5 \quad$ ICT Sector Development}

The term ICT sector comprises all professional fields concerning the research, the design, the development and the management of IT products and the telecommunications, as well as the software development industry. According to the 2010 report on R\&D in ICT in the European Union (Turlea, 2010), the ICT sector could be classified into two subsectors:

- Manufacturing, containing IT equipment, Telecom and Multimedia equipment, as well as measurement instruments

- Services, which could be computer services and software or telecommunication services.

ICT services could be produced by the companies themselves or be provided through other operators. Expected benefits from the incorporation of ICT services may be the increase in productivity and the upgrading of products or services provided, acceleration and facilitation of specific processes such as communication with external associates, and finally, the securing of funds and resources (Hollenstein, 2004). In order to achieve organizational success, there are required ICT projects with a detailed project plan for the desired outcomes (Bygstad \& Lanestedt, 2009).

The ICT sector could contribute decisively to the organization and internationalization of Research and Development (R\&D), establishing ICT R\&D centers in emerging economies and hence accelerate the growth and innovation for the industry (Hanna, 2010).

The ICT sector is one of the most important areas for the global economy, due to the growing demand for automation and digitization of both the private and public sector. Reduced cost of computer technology has led many companies and organizations to the computerization and the replacement of low qualified workers performing routine tasks. These workers have passed to service occupations which due to the increased required skills are difficult to be automated (David \& Dorn, 2013). The ICT sector is one of the most innovative and productive in the European Union. Due to the fast growth of the ICT sector and the high competition worldwide, innovation in ICT is critical for Europe's competitiveness. The integration of ICTs in the public sector and the utilization of ICTs for some major challenges in EU such as the ageing population, the improvement of living standards, as well as the upgrade of health and environment services are of paramount importance (Wintjes \& Dunnewijk, 2008).

Colombo, Croce \& Grilli (2013) evaluated the impact of the adoption of broadband Internet technology on the productivity of small and medium enterprises (SMEs). According to the results of the study, SMEs could benefit from the adoption of selected advanced broadband applications only under specific conditions, always depending on the sector in which they operate and the condition to make strategic and organizational changes.ICT businesses will have to adjust their strategy in order to reap the benefits of the wider development of the industry. 


\section{$6 \quad$ Entrepreneurship}

The growing interest in women's entrepreneurship in recent years is due to the general trend of the global economy to entrepreneurship, as well as to the perception that female led micro and small enterprises could lead to significant effect on overall household well-being (Minniti \& Naudé, 2010). The size of the public sector has a significant impact on entrepreneurship rates for both sexes, but the negative effects are more highly visible on female entrepreneurship. Furthermore, some restrictions in relation to the female freedom of movement contribute negatively to the aspiration of women to take care of business (Estrin and Mickiewicz, 2011).

Even if gender equality and women empowerment are consistently promoted, male or female stereotypes could affect a woman's decision to become an entrepreneur. Policy makers should focus on how to eliminate such beliefs in order to encourage women's entrepreneurship (Kobeissi, 2010). Women, at a much greater proportion than men, consider that values such as respect, initiative and achievement, are crucial in the decision to become entrepreneurs (Terrell \& Troilo, 2010).

Women face various problems associated with entrepreneurship, such as marketing problems due to poor location of their unit or through competition from large units, financial problems like shortage of funds and health problems may be due to lack of rest (Nayyar et al, 2007).

According to the Statistical Data on Women Entrepreneurs in Europe (European Commission, 2014) women entrepreneurs represent $29 \%$ of entrepreneurs in Europe, which means about 11.6 million people. Since 2008 there has been a slight increase of female entrepreneurs in the European Union of around 3\%, while in Europe overall women are the overwhelming majority in the one-person business (78\%).

According to data provided by the European Commission, women entrepreneurs accounted for $24 \%$ of the workforce in Greece while the corresponding percentage for the EU-28 was $10 \%$. The greatest proportions of women entrepreneurs in Greece were in sectors such as education, service activities, human health and social work activities, as well as financial and insurance activities.

Most entrepreneurs in developed or developing countries utilize ICT applications for the development of products, marketing as well as design and strategic objectives. Despite the hampering factors for female entrepreneurship, ICTs could contribute as effective tools for women to have equal opportunities with men in business development (Matthew, 2010).

\section{Conclusions}

Gender based discrimination in the workplace still exists in our days. Discrimination in relation to the role of women in the global economy, remuneration policy, career development and the patriarchal view that women have the exclusive responsibility for the care of the family. The relevant legislation for gender equality in the workplace is not sufficient to eliminate such discrimination. 
Upgrading the role of women in the labor market, either as an employee or as an entrepreneur, as well as the elimination of roadblocks and obsessions are a must for the equal right to employment regardless of gender. At the same time the new conditions formed in the labor market make ICT products and services necessary for any economy and therefore the investment in ICT is the only way for growth.

The rate at which the labor market is evolving nowadays, the creation of new jobs as well as the modernization of the existing jobs, requires continuous employee education and development of ICT-skills in order to become more competitive.

The problem of under-representation of women in the economic critical sectors such as ICTs and in conjunction with policies and EU initiatives to deal with the skills shortage in ICTs, highlights the need to design and implement actions that will activate the female population in the targeted level of training, selection and participation in entrepreneurship and employment with focus on ICTs:

- Actions that promote the participation of women in technology and entrepreneurship and create standards and benchmarks even from secondary education.

- Actions that will enhance the role of women in the field of technology and STEM education (Science, Technology, Engineering and Mathematics), either as an employee or as an entrepreneur.

- Training actions to support the entry of women into the labor market on equal terms regarding working time, remuneration and development.

In order to achieve all the above, the collaboration of all parties involved in the private and public sector is required in order to develop a national strategy based on understanding the requirements of ICTs and the dynamics of women.

\section{Acknowledgments}

This paper was supported by the European Economic Area (EEA: http://eeagrants.org/) Project entitled "e-Women: Innovation and Employability for Women".

\section{$9 \quad$ References}

[1] Arfken, D. E., Bellar, S. L., \& Helms, M. M. (2004). The ultimate glass ceiling revisited: The presence of women on corporate boards. Journal of Business ethics, 50(2), 177-186. https://doi.org/10.1023/B:BUSI.0000022125.95758.98

[2] Australia. Workforce Gender Equality Agency (WGEA). (2016). Gender pay gap statistics.

[3] Baumgartner, M. S., \& Schneider, D. E. (2010). Perceptions of women in management: A thematic analysis of razing the glass ceiling. Journal of Career Development, 37(2), 559576. https://doi.org/10.1177/0894845309352242

[4] Bierema, L. L., \& Merriam, S. B. (2002). E-mentoring: Using computer mediated communication to enhance the mentoring process. Innovative Higher Education, 26(3), 211-227. https://doi.org/10.1023/A:1017921023103 
[5] Booth, A. L., \& Van Ours, J. C. (2010). Part-time jobs: What women want?.

[6] Bosch, N., Deelen, A., \& Euwals, R. (2010). Is Part-time Employment Here to Stay? Working Hours of Dutch Women over Successive Generations. Labour, 24(1), 35-54. https://doi.org/10.1111/j.1467-9914.2010.00470.x

[7] Bureau of Labor Statistics.(2016). Current population survey annual average data tables.Table 39.www.bls.gov/cps/cpsaat39.htm.

[8] Bygstad, B., \&Lanestedt, G. (2009). ICT based service innovation-A challenge for project management. International Journal of Project Management,27(3), 234-242. https://doi.org/10.1016/j.ijproman.2007.12.002

[9] Cheung, F. M., \& Halpern, D. F. (2010). Women at the top: powerful leaders define success as work + family in a culture of gender. American Psychologist, 65(3), 182. https://doi.org/10.1037/a0017309

[10] Colombo, M. G., Croce, A., \& Grilli, L. (2013). ICT services and small businesses' productivity gains: An analysis of the adoption of broadband Internet technology. Information Economics and Policy, 25(3), 171-189. https://doi.org/10.1016/j.info ecopol.2012.11.001

[11] David, H., \& Dorn, D. (2013). The growth of low-skill service jobs and the polarization of the US labor market. TheAmericanEconomicReview, 103(5), 1553-1597.

[12] De Vries, L., Gensler, S., \& Leeflang, P. S. (2012). Popularity of brand posts on brand fan pages: An investigation of the effects of social media marketing. Journal of InteractiveMarketing, 26(2), 83-91. https://doi.org/10.1016/j.intmar.2012.01.003

[13] Doucek, P. (2011). Human capital in ICT-competitiveness and innovation potential in ICT. IDIMT, 11-22.

[14] Eagly, A. H., \& Karau, S. J. (2002). Role congruity theory of prejudice toward female leaders. Psychological review, 109(3), 573. https://doi.org/10.1037/0033-295X.109.3.573

[15] Erdoğmuş, İ. E., \&Cicek, M. (2012). The impact of social media marketing on brand loyalty. Procedia-Social and Behavioral Sciences, 58, 1353-1360. https://doi.org/10.1016/ j.sbspro.2012.09.1119

[16] Estrin, S., \& Mickiewicz, T. (2011).Institutions and female entrepreneurship. Small business economics, 37(4), 397-415. https://doi.org/10.1007/s11187-011-9373-0

[17] European Commission (2011). Europe 2020: Flagship Initiative Innovation Union

[18] European Commission. (2014). Statistical Data on Women Entrepreneurs in Europe

[19] Felstead, A., Gillie, D., \& Zhou, Y. (2007) Skills at Work, 1986-2006, ESRC Centre on Skills, Knowledge and Organisational Performance (SCOPE).

[20] Garrido, M., Sullivan, J., \& Gordon, A. (2010, December).Understanding the links between ICT skills training and employability: an analytical framework. In Proceedings of the 4th ACM/IEEE International Conference on Information and Communication Technologies and Development (p. 15).ACM.

[21] Gourova, E., Antonova, A., \&Nikolov, R. (2006).Building skills for the knowledge society. In Third International scientific conference Computer Science, Istanbul, 12-15 October 2006 (pp. 107-112).

[22] Gilster, P., \& Glister, P. (1997). Digital literacy. New York: Wiley Computer Pub..

[23] Green, F., Felstead, A., Gillie, D., \& Zhou, Y. (2007, July). Computers and pay. National Institute Economic Review, 201(1), 63-75. https://doi.org/10.1177/0027950107083051

[24] Hanna, N. K. (2010). ICT Services Industry for an Innovation Economy. In Enabling Enterprise Transformation (pp. 135-158). Springer New York. https://doi.org/10.1007/978-14419-1508-5 6

[25] Headlam-Wells, J. (2004). E-mentoring for aspiring women managers. Women in Management Review, 19(4), 212-218. https://doi.org/10.1108/09649420410541281 
[26] Headlam-Wells, J., Gosland, J., \& Craig, J. (2006). Beyond the organization: The design and management of E-mentoring systems. International Journal of Information Management, 26(5), 372-385. https://doi.org/10.1016/j.ijinfomgt.2006.04.001

[27] Hollenstein, H. (2004). Determinants of the adoption of Information and Communication Technologies (ICT): An empirical analysis based on firm-level data for the Swiss business sector. Structural change and economic dynamics, 15(3), 315-342. https://doi.org/10.1016/ j.strueco.2004.01.003

[28] Jackson, J. F., \& O'Callaghan, E. M. (2009). What do we know about glass ceiling effects? A taxonomy and critical review to inform higher education research. Research in Higher Education, 50(5), 460-482. https://doi.org/10.1007/s11162-009-9128-9

[29] Kobeissi, N. (2010). Gender factors and female entrepreneurship: International evidence and policy implications. Journal of International Entrepreneurship, 8(1), 1-35. https://doi.org/10.1007/s10843-010-0045-y

[30] Laurijssen, I., \& Glorieux, I. (2013). Career trajectories for women after childbirth: Job quality and work-family balance. European sociological review, 29(3), 426-436. https://doi.org/10.1093/esr/jcr082

[31] Lim, S., \& Cortina, L. M. (2005). Interpersonal mistreatment in the workplace: the interface and impact of general incivility and sexual harassment. Journal of applied psychology, 90(3), 483. https://doi.org/10.1037/0021-9010.90.3.483

[32] Mandel, H., \& Shalev, M. (2009). How welfare states shape the gender pay gap: a theoretical and comparative analysis. Social Forces, 87(4), 1873-1911. https://doi.org/10.1353/ sof. 0.0187

[33] Mathew, V. (2010). Women entrepreneurship in Middle East: Understanding barriers and use of ICT for entrepreneurship development. International Entrepreneurship and Management Journal, 6(2), 163-181. https://doi.org/10.1007/s11365-010-0144-1

[34] Minniti, M., \&Naudé, W. (2010). What do we know about the patterns and determinants of female entrepreneurship across countries?. The European Journal of Development Research, 22(3), 277-293. https://doi.org/10.1057/ejdr.2010.17

[35] Nayyar, P., Sharma, A., Kishtwaria, J., Rana, A., \& Vyas, N. (2007). Causes and constraints faced by women entrepreneurs in entrepreneurial process. The Journal of Social Science, 14(2), 99-102.

[36] Roberts, B. S., \& Mann, R. A. (1995). Sexual harassment in the workplace: A primer. Akron L. Rev., 29, 269.

[37] Roztocki, N., \&Weistroffer, H. R. (2009). Research trends in information and communications technology in developing, emerging and transition economies. Collegium of Economic Analysis, 20, 113-127.

[38] Tackling the gender pay gap in the European Union

[39] Terrell, K., \&Troilo, M. (2010).Values and female entrepreneurship. International Journal of Gender and Entrepreneurship, 2(3), 260-286. https://doi.org/10.1108/175662610110 79242

[40] Turlea, G., Nepelski, D., De Prato, G., Lindmark, S., de Panizza, A., Picci, L., ...\&Broster, D. (2010). The 2010 report on R\&D in ICT in the European Union. JRC Scientific and Technical Report, JRC-IPTS. Available at: http://ipts. jrc. ec.europa. eu/publications/pub. cfm.

[41] Underwood, J., \& Khosrowshahi, F. (2012).ICT expenditure and trends in the UK construction industry in facing the challenges of the global economic crisis. Journal of Information Technology in Construction, 17, 26-41.

[42] Vanderpool, C., \& Way, S. A. (2013).Investigating work-family balance, job anxiety, and turnover intentions as predictors of health care and senior services customer-contact em- 
ployee voluntary turnover. Cornell Hospitality Quarterly, 54(2), 149-160. https://doi.org/10.1177/1938965513478682

[43] Várallyai, L., \&Herdon, M. (2010).E-SKILLS EFFECTS TO LABOUR MARKET. The Economies of Balkan and Eastern Europe Countries in the changed world, 21.

[44] Violence against women: an EU-wide survey Main results, (2014). European Union Agency for Fundamental Rights.

[45] Willness, C. R., Steel, P., \&Lee, K. (2007).A meta-analysis of the antecedents and consequences of workplace sexual harassment. Personnel Psychology,60(1), 127-162. https://doi.org/10.1111/j.1744-6570.2007.00067.x

[46] Wintjes, R. E. N. É., \&Dunnewijk, T. H. E. O. (2008). Sectoral innovation systems in Europe: The case of the ICT sector. Europe-Innova, 9.

\section{Authors}

Marios Pappas (B.Sc., M.Ed.) is a research associate at N.C.S.R. Demokritos, Institute of Informatics and Telecommunications, Net Media Lab, Athens, Greece (email: mpap@iit.demokritos.gr ).

Yannis Papagerasimou (B.Sc., M.Sc.) holds a Bachelor degree in Electronic and Computer Engineering and a Master's degree in Data Communications. He is a research associate at N.C.S.R. Demokritos, Institute of Informatics and Telecommunications, Net Media Lab, Athens, Greece (e-mail: ypapa@iit.demokritos.gr).

Athanasios Drigas is a Director of Research at IIT - N.C.S.R. Demokritos. He is the Coordinator of Telecoms Lab and founder of Net Media Lab since 1996. From 1990 to 1999 he was the Operational manager of the Greek Academic network. He has been the Coordinator of Several International Projects, in the fields of ICTs, and e-services (e-learning, e-psychology, e-government, e-inclusion, e-culture etc). He has published more than 280 articles, 7 books, 25 educational CD-ROMs and several patents. He has been a member of several International committees for the design and coordination of Network and ICT activities and of international conferences and journals. (e-mail: dr@iit.demokritos.gr).

Dimitris Raftopoulos (B.Sc., M.Sc.) is a research associate at N.C.S.R. Demokritos, Institute of Informatics and Telecommunications, Net Media Lab, Athens, Greece (e-mail: dimitris@ecwt.eu).

Pantelis Nikolaidis (B.Sc., M.Sc.) is a research associate at N.C.S.R. Demokritos, Institute of Informatics and Telecommunications, Net Media Lab, Athens, Greece (email: pnikolai@otenet.gr).

Article submitted 10 February 2017. Published as resubmitted by the authors 15 April 2017. 